\title{
The VPAC1 receptor: structure and function of a class B GPCR prototype
}

\author{
A. Couvineau*, E. Ceraudo, Y.-V. Tan, P. Nicole and M. Laburthe* \\ Faculté de Médecine Xavier Bichat, INSERM 773/Centre de Recherche Biomédicale Bichat Beaujon (CRB3), Université Paris 7, Paris Cedex 18, France
}

\section{Edited by:}

Hubert Vaudry, University of Rouen,

France

\section{Reviewed by:}

James Waschek, University of California at Los Angeles, USA

Daniel Fourmy, University of

Toulouse 3, France

*Correspondence:

A. Couvineau and M. Laburthe, Faculté de Médecine X. Bichat, INSERM U773/CRB3, 16 Rue Henri Huchard, 75018 Paris, France. e-mail: alain.couvineau@inserm.fr; marc.laburthe@inserm.fr
The class B G protein-coupled receptors (GPCRs) represents a small sub-family encompassing 15 members, and are very promising targets for the development of drugs to treat many diseases such as chronic inflammation, neurodegeneration, diabetes, stress, and osteoporosis. The VPAC1 receptor which is an archetype of the class B GPCRs binds Vasoactive Intestinal Peptide (VIP), a neuropeptide widely distributed in central and peripheral nervous system modulating many physiological processes including regulation of exocrine secretions, hormone release, foetal development, immune response ... VIP appears to exert beneficial effect in neurodegenerative and inflammatory diseases. This article reviews the current knowledge regarding the structure and molecular pharmacology of VPAC1 receptors. Over the past decade, structure-function relationship studies have demonstrated that the $\mathrm{N}$-terminal ectodomain ( $\mathrm{N}$-ted) of VPAC1 plays a pivotal role in VIP recognition. The use of different approaches such as directed mutagenesis, photoaffinity labeling, Nuclear Magnetic Resonance (NMR), molecular modeling, and molecular dynamic simulation has led to demonstrate that: (1) the central and Cterminal part of the VIP molecule interacts with the N-ted of VPAC1 receptor which is itself structured as a $\ll$ Sushi $\gg$ domain; (2) the N-terminal end of the VIP molecule interacts with the first transmembrane domain of the receptor where three residues $\left(\mathrm{K}^{143}, \mathrm{~T}^{144}\right.$, and $\left.\mathrm{T}^{147}\right)$ play an important role in VPAC1 interaction with the first histidine residue of VIP.

Keywords: GPCR, photolabeling, VPAC1, VIP, mutagenesis, inflammation, neuroprotection, molecular modeling

\section{INTRODUCTION}

Vasoactive Intestinal Peptide (VIP) discovered by Said and Mutt (1970) is an ubiquitous 28-aminoacid neuropeptide that is widely distributed in central and peripheral nervous system. During the past 10 years, VIP was also identified in the immune system where it plays the role of a "cytokine-like peptide" (Delgado et al., 2004). VIP plays an important role in human physiology (Table 1) such as in development, growth, immune responses, circadian rhythms, neuronal and endocrine control, neuroprotective actions, and in the functions of the digestive, respiratory, reproductive, and cardiovascular systems (Laburthe et al., 2007). Associated to its large distribution and biological functions, VIP may also play a role in various pathologies (Table 1). It has been identified as a very promising agent in the treatment of inflammatory and neurodegenerative diseases (Gozes et al., 2003; Delgado et al., 2004). Indeed, VIP appears to be a very potent anti-inflammatory peptide in animal models of Crohn disease (Abad et al., 2003), rheumatoid polyarthritis (Delgado et al., 2001), or septic shock. This neuropeptide belongs to the structural-related peptide named secretin/VIP family (Table 2) encompassing VIP, pituitary adenylate cyclase

List of non-standard abbreviations: VIP, Vasoactive Intestinal Peptide; PACAP, Pituitary Adenylate Cyclase Activating Peptide; VPAC, VIP and PACAP receptor; Bpa, Benzophenone; N-ted, N-terminal ectodomain; ITF, Intrinsic Tryptophan Fluorescence. activating peptide (PACAP), secretin, growth hormone releasing factor (GRF), peptide having an histidine residue in N-terminal position and an isoleucine residue in C-terminal position ( $\mathrm{PHI}$ and its human homolog PHM), helodermin, glucagon, gastric inhibitory polypeptide (GIP), glucagon-like peptide 1 and 2 (GLP-1 and GLP-2).

\section{VIP A POTENTIAL THERAPEUTICAL AGENTS}

Few years ago, VIP emerged as a potential therapeutic agent for various diseases including asthma (Groneberg et al., 2006), sexual impotence (Fahrenkrug, 2001), brain strokes (Dogrukol-Ak et al., 2004), chronic inflammation (Delgado et al., 2004), neurodegenerative disorders (Dejda et al., 2005), and cancers (Moody et al., 2011). Recently, a lot of reports have focused on the role of VIP and its receptors in chronic inflammation and neurodegenerative diseases.

VIP has been identified as a very promising agent in treatment of inflammatory diseases (Delgado et al., 2004). Indeed, VIP appeared to be a very potent anti-inflammatory peptide in animal models of various chronic inflammatory diseases (Couvineau and Laburthe, 2012a,b). The VIP anti-inflammatory effect has been widely studied (Delgado et al., 2004). These studies showed, in homeostasis condition, innate and adaptive immunity, that VIP can help to preserve the equilibrium between pro-inflammatory and anti-inflammatory response. In chronic 
Table 1 | Major physiological and pathophysiological actions of VIPa .

\begin{tabular}{ll}
\hline Short-term & $\begin{array}{l}\text { Neurotransmition, exocrine secretions (water, ions), } \\
\text { hormone release (prolactin, luteinizing hormone, growth } \\
\text { hormone, insulin...), muscle relaxation (vasodilator, } \\
\text { bronchodilator, gastro-intestinal motility), metabolism }\end{array}$ \\
Long-term & $\begin{array}{l}\text { Circadian rhythms, learning and behavior, growth } \\
\text { regulator of whole fetuses and embryonic brain }\end{array}$ \\
Other effects & $\begin{array}{l}\text { Neuroprotection, suppression of inflammation, } \\
\text { immunomodulation, effects on cell proliferation in cancer }\end{array}$
\end{tabular}

${ }^{a}$ Reviewed in Gozes et al. (2003); Dickson and Finlayson (2009); Delgado and Ganea (2011); Moody et al. (2011); Harmar et al. (2012).

Table 2 | Sequence alignments of class B GPCR ligands ${ }^{b}$.

\begin{tabular}{|c|c|c|}
\hline $\mathrm{VIP}^{a}$ & 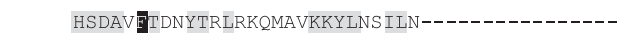 & $28^{b}$ \\
\hline PACAP27 & HSDGI TIDSYSRYRKQMAVKKYLAAVL ---------------- & 27 \\
\hline PACAP38 & HSDGI TTDSYSRYRKQMAVKKYLAAVLGKRYKQRVKNK------ & 38 \\
\hline Helodermin & HSDAI & 35 \\
\hline PHM & HADGVGTSDFSKLLGQLSAKKYLESLM------- & 27 \\
\hline Secretin & HSDGT TSELSRLREGARLQRLLQGLV & 27 \\
\hline GRF & YADAI TINSYRKVLGQLSARKLLQDIMSRQQGESNQERGARARL & 44 \\
\hline Glucagon & HSQGT TISDYSKYLDSRRAQDFVQWLMNT-- & 29 \\
\hline GLP-1 & HAEGT GTSDVSSYLEGQAAKEFIAWLVKGR------------ & 30 \\
\hline GLP-2 & HADGS SDEMNTILDNLAARDFINWLIQTKITD----------- & 33 \\
\hline GIP & YAEGT ISDYSIAMDKI HQQDFVNWLLAQKGKKNDWKHNITQ-- & 42 \\
\hline PTH & ---SVSEIQLMHNLGKHLNSMERVEWLRKKLQDVHNF & 34 \\
\hline PTHrP & ---AVSEHQLLHDKGKS IQDLRRRFFLHHL IAEIHTA---- & 34 \\
\hline Calcitonin & ----CGNLSTCMLGTYTQDFNKFHTFPQTAIGVGAP----- & 32 \\
\hline CRF & SEEPPISLDLTFHLLREVLEMARAEQLAQQAHSNRKLMEI I & 41 \\
\hline
\end{tabular}

${ }^{a}$ Black boxes represent sequence identity and light gray boxes represent sequence homology.

${ }^{b}$ Numbers indicate the length of the peptides.

inflammatory diseases (Crohn disease, rheumatoid polyarthritis, hepatitis, encephalomyelitis...) a modification of this equilibrium can be induce by various stimuli such as pathogenic agents, auto-immunity, environment, genetic background... which lead to the stimulation of production of pro-inflammatory cytokines (IL-17, IL-1, IFN $\gamma, \mathrm{TNF} \alpha . .$. ) by macrophages and lymphocytes $\mathrm{T}$ (Th1 and Th17). Conversely, the anti-inflammatory response mediated by anti-inflammatory cytokines (IL-10, IL-4, IL-13, TGF $\beta . .$. ) secreted by lymphocytes T (Th2 and Treg), was strongly inhibited. The VIP anti-inflammatory effect involves a "rebalancing" of immune system (Firestein, 2001) by inhibition of pro-inflammatory response (Th1 and Th17) and stimulation of anti-inflammatory response mediated by Th2 and Tregs. In parallel, VIP induces an inhibitory effect on innate immunity by inhibition of production of pro-inflammatory cytokines and chemokines secreted by macrophage. Moreover, VIP is able to strongly inhibit the production of reactive oxygen species (ROS) induced by fMLP in monocytes (personnal data). Moreover, various reports clearly demonstrate that VIP promotes tolerance by inducing expansion of Treg cells (Leceta et al., 2007). Whereas, some reports reveal that VIP-deficient mice are resistant to the development of induced-encephalomyelitis or inducedendotoxemia indicating that in these conditions VIP plays unexpected permissive and/or pro-inflammatory actions (Abad et al., 2010, 2012). Despite this effect, VIP represents a potential anti-inflammatory agent that could be used in human therapeutic treatment, although the VIP anti-inflammatory effects have been mainly described in animal models (Couvineau and Laburthe, 2012a,b). Whereas, the major obstacle to the use of VIP in clinic therapies is its high sensitivity to protease degradation. Indeed, removing of the first residues by peptidases, such as dipeptidyl peptidase IV (DPPIV), induces a drastic loss of affinity of VIP peptide family (Lambeir et al., 2001). To circumvent these labile properties, VIP can be modified to increase its resistance to degradation by $\mathrm{N}$-acylation of the peptide N-terminal end or by substitution of residues involved in proteolytic consensus sequences (dibasic doublets). Recent data indicate that PACAP N-terminal modifications confer resistance to DPPIV (Bourgault et al., 2008). In the same way acetylation of the VIP N-terminal end increase its stability in the presence of human serum (personal data). Other strategies consist to protect peptide against degradation by insertion of VIP into micelles or nanoparticles (Fernandez-Montesinos et al., 2009; Onyüksel et al., 2009). Despite these limitations, VIP has been tested in a phase I clinical trial for the treatment of acute respiratory distress syndrome and sepsis (id: NCT00004494, http://www.clinicaltrials.gov).

In the mid-1980s, the first report of VIP neuroprotection, demonstrated that this peptide is able to prevent neuronal death associated with electrical blockade induced by tetrodotoxin (TTX) addition to primary spinal cord cultures (Brenneman and Eiden, 1986). Further studies have demonstrated that VIP plays a neuroprotective effects in various neurodegenerative diseases developed in animal models including Alzheimer's disease (Gozes et al., 1996), Parkinson's disease or encephalomyelitis (Gonzalez-Rey et al., 2005; Tan and Waschek, 2011). Some of these VIP neuroprotective actions were associated with glial cells possessing VPAC receptors. Clearly, VIP induced, on glial cells, a secretion of various trophic molecules having neuroprotective properties such as IL-1, IL-6, protease nexin-1, the chemokine RANTES and MIP (Dejda et al., 2005). Moreover, VIP inhibits the production of pro-inflammatory cytokines as $\mathrm{TNF} \alpha$ and/or IL- $1 \beta$ secreted by activated microglia which is involved in neuroinflammation observed in Parkinson's disease or brain trauma models (Delgado et al., 2004). VIP also induces neuroprotective effect by increasing the secretion of activity-dependent neurotrophic factor (ADNF) and/or activitydependent neurotrophic protein (ADNP) (Gozes et al., 2003). These two protective proteins, which belong to the heat shock protein family, are able to prevent the neuronal death (Dejda et al., 2005) and represent one of the most potent neuroprotective agents secreted by astroglia in response to VIP. Recently, it was suggested that the VPAC2 receptor, which binds VIP and/or PACAP with the same affinity, could be a potential target for the development of anti-psychotic drugs. Effectively, the VPAC2 receptor gene has been found to be duplicated in schizophrenia (Vacic et al., 2011). Although VIP is able to cross the brain blood barrier (Dogrukol-Ak et al., 2004), no clinical trials in humans were developed to evaluate its neuroprotective role in brain diseases. However, some human clinical trials based on VIP vasoactive properties on cerebral arteries and hemodynamics have been performed (id: NCT00272896 and NCT00255320 
http://www.clinicaltrials.gov) to evaluate its role in development of headache/migraine.

\section{VPAC RECEPTORS, A REPRESENTATIVE MEMBERS OF CLASS B GPCR}

Biological responses induced by VIP are triggered by interaction with two receptors, VPAC1 and VPAC2, which are mainly coupled to the G-protein, Gs, resulting in the stimulation of cell adenylyl cyclase (Couvineau et al., 2010). Furthermore, some groups have reported the ability of VIP to increase calcium levels in different cells (Dickson and Finlayson, 2009). Moreover, VPAC1 receptor is able to interact with RAMP (Receptor Activity-Modifying Proteins) proteins, in particular RAMP2, inducing a significant enhancement of agonist-mediated inositol triphosphate production but do not modify the coupling to adenylate cyclase (Christopoulos et al., 2002). VPAC1 and VPAC2 receptors bind, with the same affinity, VIP and another neuropeptide named PACAP. It should be noted that VIP interacts also with the specific PACAP receptor (PAC1) but with a lower affinity (Couvineau and Laburthe, 2012a). Previous report indicate that VPAC1 receptor is able to homo-dimerize and hetero-dimerize with VPAC2 or secretin receptors (Harikumar et al., 2006). However, the relation between receptor oligomerization and the ability to VPAC1 receptor to interact with RAMPs remains unclear.

In the nineties secretin and VPAC receptors have been cloned (Ishihara et al., 1991, 1992; Lutz et al., 1993; Sreedharan et al., 1993; Couvineau et al., 1994) revealing a new G protein-coupled receptor (GPCR) sub-family termed class B GPCR. This GPCR sub-family shares with the other GPCR classes (A, C, D, E, F) the same general structural scheme characterized by the presence of seven-transmembrane helices denoted as TM I through TM VII which are interconnected by extracellular and intracellular loops (Fredrikson and Schiöth, 2006). The class B receptors family is composed of 15 members including receptors for VIP, PACAP, secretin, glucagon, glucagon-like peptide-1, glucagonlike peptide-2, GRF, GIP, and also include receptors for parathyroid hormone, calcitonin, calcitonin gene-related peptide, and corticotropin-releasing factor (CRF) (Couvineau and Laburthe, 2012b). Class B receptors display very low sequence homologies with others GPCRs (Laburthe et al., 2007) and share several specific characteristics: the presence of a large (>120 residues) and structured $\mathrm{N}$-terminal ectodomain ( $\mathrm{N}$-ted) which is usually small in most class A GPCRs. The N-teds contain six highly conserved cysteine residues connected by three disulfide bridges, this sequence is the signature of class B GPCRs. The N-ted of class B receptor which represents the major binding site for its cognate natural peptide ligand, is characterized by; (1) the presence of a signal peptide probably involved in insertion of receptor in plasma membrane; (2) the absence of archetypical class A GPCR motifs such as E/D-R-Y or NP-xx(x)-Y; (3) a complex gene organization with many introns (Laburthe et al., 2002).

Currently, no data are available regarding the full-length structure of class B receptors as compare to class A receptors (Shoichet and Kobilka, 2012), although the structural properties of the class B GPCR N-ted, have recently been described, representing the first step toward better understanding of the binding receptor site at the atomic level. Recently, six N-ted structures, including those of the human PACAP receptor (PAC1), human PTH receptor (PTH1R), human GLP-1 receptor (GLP-1R), human GIP receptor (GIPR), and human type- 1 and type-2 CRF receptor (CRFR1 and CRFR2) have been elucidated by Nuclear Magnetic Resonance (NMR) spectroscopy and X-ray crystallography in the presence of bound antagonist or agonists (Couvineau et al., 2010). These studies reveal the presence in the N-ted of a common core (Figure 1) formed by a Sushi domain (Parthier et al., 2009; Pal et al., 2012). This shared structure is composed of two anti-parallel $\beta$ sheets (Figure 1) stabilized by (1) three disulfide bonds involving the typical six highly conserved cysteine residues (Figure 1); (2) a putative salt bridge involving acidic and basic residues, sandwiched between hydrophobic aromatic rings (Figure 1). The high conservation of the Sushi domain in the Nted of class B GPCRs supports the idea that this structure plays a crucial role for peptide recognition (Grace et al., 2004). A "twosite" model for the binding of native ligands to class B GPCRs has been postulated (Hoare, 2005). In short, the central and the C-terminal portions of the peptide ligand are captured by the $\mathrm{N}$ ted of the class B GPCRs. This step is essential for the peptide structuration, allowing the ligand $\mathrm{N}$-terminus to interact with the transmembrane region of the receptor (Hoare, 2005).

As mentioned above VIP belongs to the secretin/VIP/PACAP family. The emergence of the class B GPCR has enlarged this peptide family (Table 2) by including parathyroid hormone (PTH), calcitonin, and CRF. All these natural ligands share some common properties: (1) they are all peptides with 27-44 amino acid residues; (2) they are synthesized and released by endocrine cells, neurons, and/or immune cells; (3) all these peptides exhibit a marked propensity to form $\alpha$-helices; (4) all these peptides contain a N-Cap structure in the N-terminal part (Neumann et al.,

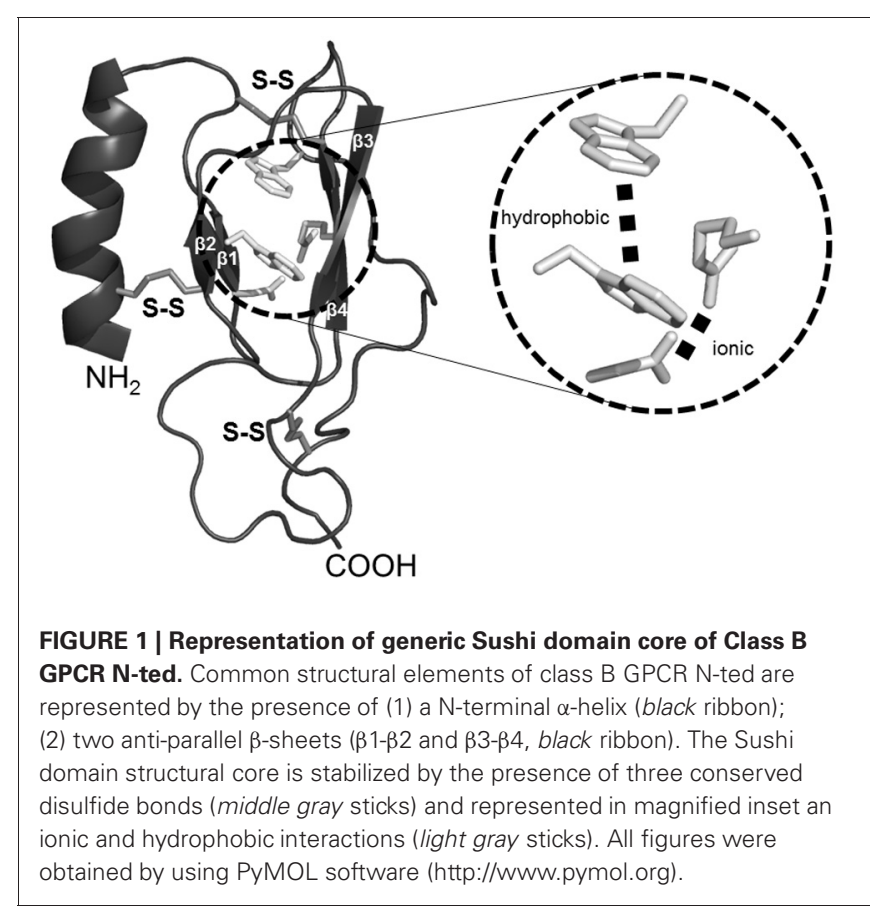


2008). The presence of this structural signature which includes a hydrophobic cluster between $\mathrm{N}$-terminal hydrophobic residues and a hydrogen bond between two polar residues (Figure 2) have been recently confirmed (Watkins et al., 2012). All these peptides play an important role in physiological processes and strongly impact human physiopathology including chronic inflammation diseases, neurodegenerative disorders, schizophrenia, diabetes, osteoporosis, stress (Couvineau and Laburthe, 2012a).

Cloning of the human VPAC1 receptor (Couvineau et al., 1994) allowed its extensive studied for many years by site-directed mutagenesis and molecular chimerism (Laburthe et al., 2007) laying its molecular basis in terms of: (1) affinity (Couvineau et al., 1995); (2) specificity (Couvineau et al., 1996a); (3) cellular addressing (Couvineau et al., 2004); (4) desensitization (Marie et al., 2003); (5) association with RAMP proteins (Christopoulos et al., 2002); (6) adenylyl cyclase coupling (Couvineau et al., 2003). These studies have revealed that the receptor $\mathrm{N}$-ted plays a crucial role in peptide agonist binding (Couvineau et al., 2010). In parallel, structure-function relationships analysis of VIP by a complete alanine scanning (Nicole et al., 2000) showed that the peptide has a diffuse pharmacophoric domain. In this study we have demonstrated that the N-terminal 1-5 segment plays a crucial role in receptor activation e.g., mainly adenylyl cyclase activation.

\section{THE VPAC1 BINDING SITE, CONTRIBUTION OF PHOTOLABELING APPROACH}

The physical interaction sites between VIP and the VPAC1 receptor had remained elusive until the development of a photoaffinity labeling strategy, which allowed the demonstration that VIP side chains are physically in contact with the N-ted of VPAC1 (Couvineau et al., 2010). This strategy has two advantages over structural studies of purified recombinant receptors or receptor

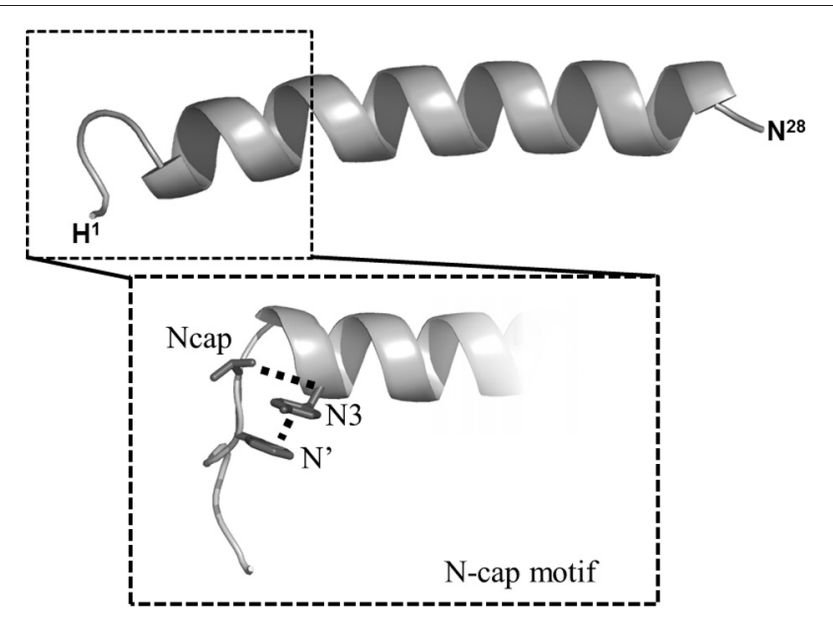

FIGURE 2 | NMR structure of VIP and representation of N-capping motif. Middle gray ribbon represents the average conformation of VIP structure. In magnified inset the N-capping motif is represented as (1) the hydrophobic interactions between side-chain groups of $\mathrm{N}^{\prime}$ and $\mathrm{N} 3$ residues (dashed lines); (2) the hydrogen bond between side chain of $\mathrm{N}$-cap residue and backbone atom of N3 residue. See ref. Neumann et al. (2008) for details. fragments: (1) the labeled ligand has an affinity for its receptor in the nanomolar range, which is similar to the high affinity measured under physiological conditions; and (2) the labeled ligand can interact with the glycosylated native receptor expressed in plasma membranes of eukaryotic cells. This is particularly important, given to the critical role of glycosylation in VPAC1 expression and function (Couvineau et al., 1996b). Addition of a benzophenone group (Bpa) to the VIP peptide has extensively contributed to the elucidation VIP biochemistry and of its receptor (Couvineau and Laburthe, 2012b). The use of photolabeling probes has clearly demonstrated that VIP residues in position 0 , $6,22,24$, or 28 were in physical contact with different amino acids in N-ted of the VPAC1 e.g., Gln ${ }^{135}$, Asp ${ }^{107}, \mathrm{Gly}^{116}$, Cys ${ }^{122}$, and Lys ${ }^{127}$ (Figure 3), respectively (Tan et al., 2003, 2004, 2006; Ceraudo et al., 2008, 2012). To dock VIP within the receptor $\mathrm{N}$-ted, we determined the structure of VIP by NMR (Figure 2) and also developed a structural model of the VPAC1 receptor N-ted (Tan et al., 2006). Determination of VIP structure by NMR revealed that most of the 28 amino acids sequence has an $\alpha$-helice structure (sequence $7-28$ ) with the exception of the N-terminal 1-5 sequence, which has no defined structure in solution (Figure 2). In parallel, the structural model development of the VPAC1 receptor N-ted, by homology with the NMR structure of the CRF $2 \beta$ receptor $\mathrm{N}$-ted, allowed us to localize the VIP binding site in the N-ted. As expected, the structure contains two anti-parallel $\beta$ sheets that are stabilized by three disulfide bonds between residues $\mathrm{Cys}^{50}$ and $\mathrm{Cys}^{72}$, $\mathrm{Cys}^{63}$ and $\mathrm{Cys}^{105}$, and $\mathrm{Cys}^{86}$ and $\mathrm{Cys}^{122}$, and by a putative salt bridge involving Asp ${ }^{68}$. $\mathrm{Arg}^{103}$, sandwiched between the aromatic rings of $\operatorname{Trp}^{73}$ and $\operatorname{Tr} \mathrm{p}^{110}$ (Figure 3). The NMR structure of VIP has been docked in the VPAC1 receptor $\mathrm{N}$-ted giving rise to a valid model in which, the N-ted C-terminal part, nicely accommodates the VIP molecule at least for the 6-28 sequence (Figure 3). This model has

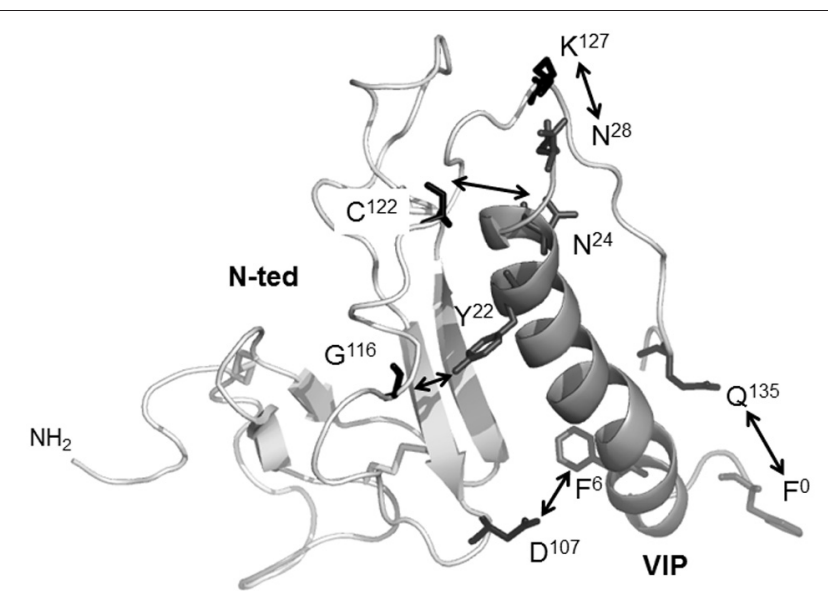

FIGURE 3 | The 3D-structural model of VPAC1 receptor $\mathrm{N}$-ted and docking of VIP. Ribbon representation of the VPAC1 N-ted: light gray ribbon, main chain; white ribbon, VIP. Docking calculations showed that $\mathrm{Q}^{135}, \mathrm{D}^{107}, \mathrm{G}^{116}, \mathrm{C}^{122}$, and $\mathrm{K}^{127}$ residues (middle gray sticks) present in the $\mathrm{N}$-ted were in contact ( $w$ hite arrows) with the side chains of $\mathrm{F}^{0}, \mathrm{~F}^{6}, \mathrm{Y}^{22}$, $\mathrm{N}^{24}$, and $\mathrm{N}^{28}$ (black sticks) of VIP residues, respectively. Figure was obtained by using PyMOL software (http://www.pymol.org). 
been submitted to molecular dynamic simulations over $14 \mathrm{~ns}$ in a water box and appears to be highly stable (Ceraudo et al., 2008).

Recently, using similar strategy, we have characterized the interaction site of the VPAC1 receptor-specific VIP antagonist, [Ac-His ${ }^{1}, \mathrm{D}-\mathrm{Phe}^{2}, \mathrm{~K}^{15}, \mathrm{R}^{16}$, $\mathrm{L}^{27}$ ] VIP(3-7)/GRF(8-27) or PG 97269 (Gourlet et al., 1997). This antagonist is a chimeric peptide between VIP (sequence 1-7) and GRF (sequence 8-27) having a D-phenylalanine residue in position 2. The use of Bpa ${ }^{0}$-PG97-269 affinity labeling probe revealed that the $\mathrm{N}$-terminal part of antagonist physically interacted with Gly ${ }^{62}$ residue of VPAC1 N-ted (Ceraudo et al., 2012). These observations clearly support that the N-terminal part of VIP (agonist) or PG97-269 (antagonist) were recognized by two different domains present in $\mathrm{N}$-ted of VPAC1 receptor.

As mentioned above, the $\mathrm{N}$-ted structure of different class B GPCRs has been obtained recently by X-ray crystallography or NMR spectroscopy (Parthier et al., 2009). These studies seem to indicate the existence of two different binding sites for ligands in class B receptor N-teds (Couvineau et al., 2010). Analysis of these structure and/or molecular models revealed that $\mathrm{N}$-teds of GIPR, PTHR, CRF1R, CRF2R, and GLP-1R interact with ligands in regions encompassing the loop located between $\beta 1$ and $\beta 2$ sheets and the loop located between $\beta 3$ and $\beta 4$ sheets (Parthier et al., 2009). In contrast, the N-teds of PAC1R and VPAC1R bind peptides along $\beta 3$ and $\beta 4$ sheets of the sushi domain (Couvineau et al., 2010). However, a recent report based on the X-ray crystallography analysis of $\mathrm{PAC1}$ receptor $\mathrm{N}$-ted and the docking of PACAP indicates that PACAP could interact with its receptor as GIPR, PTHR, CRF1R, CRF2R, and GLP-1R (Kumar et al., 2011). The real significance of these differences were unclear but may be tentatively related to the following interpretations: (1) some structural determinations were carried-out in presence of ligands which have a low affinity (micromolar range) for the recombinant $\mathrm{N}$-ted whereas in other studies ligand affinity was higher; it also could be hypothesized that low and high affinity binding occur at different sites in the N-ted structure; (2) the determination of interaction between $\mathrm{N}$-teds and ligands was mainly obtained in the presence of antagonist but it some cases in the presence of an agonist; (3) moreover it could be hypothesized that agonists and antagonists bind to different domains in the N-teds. Finally, we cannot exclude the possibility that ligands can bind by two different ways to N-ted of class B GPCR.

\section{THE KEY ROLE OF THE FIRST TRANSMEMBRANE DOMAIN OF VPAC1 IN VIP BINDING}

VPAC1 domain interacting with the N-terminus of VIP (1-5) is still unknown. Up to now, no data are available regarding the fulllength structure of class B receptors. To circumvent this unavailability, a 3D-model of the receptor encompassing VIP/N-ted complex and the transmembrane core of the receptor (Figure 4) was developed (Ceraudo et al., 2012). The 3D-model of the transmembrane core was constructed by homology modeling based on the recent determination of the X-ray structure of the adenosine A2A receptor (Jaakola et al., 2008). The resulting 3D-model of VPAC1 revealed that the central and C-terminal residues of VIP are in contact with $\mathrm{N}$-ted whereas the N-terminus of VIP lies in a pocket formed by the extracellular side of the first, second

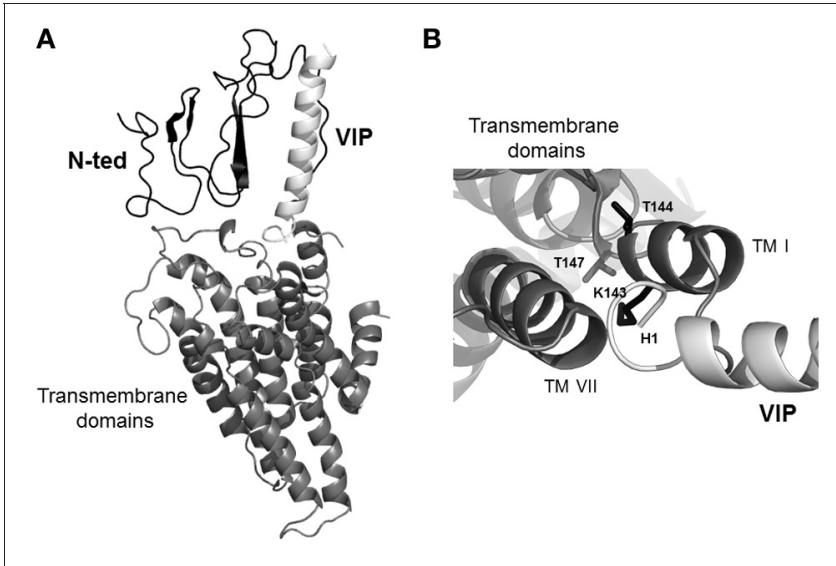

FIGURE 4 | Representation of global 3D-model of VPAC1 docked to VIP. (A) 3D-global model of human VPAC1 based on X-ray structure of the A2A receptor. (B) Upside view of 3D-global model of human VPAC1 displaying side-chains of residues of the 3D-global model of the receptor (black sticks) in close contact (distance $<6 \AA$ ) with the N-terminal end of VIP (white). middle gray ribbon, transmembrane domains; black ribbon, main chain of $\mathrm{N}$-ted; white ribbon, main chain of VIP.

and seventh transmembrane domains and the second extracellular loop of VPAC1 (Figure 4A). Based on distance calculation $(<6 \AA)$ between residues of VPAC1 and VIP, substitutions by alanine of residues revealed that many residues are involved in the binding affinity of VIP to VPAC1. Three of them $\left(\mathrm{H}^{112}, \mathrm{~L}^{131}\right.$, and $\left.\mathrm{Q}^{134}\right)$ are present in the $\mathrm{N}$-ted, and their substitution to alanine induced an affinity modification of about 100 times as compared to native receptor, indicating that these residues are probably involved in the interaction between the $\mathrm{N}$-ted and the central and C-terminal parts of VIP (Ceraudo et al., 2012). Substitution to alanine of four other residues $\left(\mathrm{K}^{143}, \mathrm{~T}^{144}, \mathrm{~T}^{147}\right.$, and $\left.\mathrm{L}^{375}\right)$ located in the extracellular side of TMI and VII, also induced a strong modification of receptor affinity for VIP (Ceraudo et al., 2012). Moreover site-directed mutagenesis experiments and reciprocal exchange between $\mathrm{K}^{143}, \mathrm{~T}^{144}$, and $\mathrm{T}^{147}$ residues of VPAC1 and $\mathrm{H}^{1}$ of VIP, shown that this interaction with (Figure $4 \mathrm{~B}$ ) the first histidine residue of VIP play a crucial role (Ceraudo et al., 2012). This step is important for the adenylyl cyclase activation (Couvineau et al., 1984). These observations were in good agreement with previous results indicating that $\mathrm{D}^{196}$ present in the second extracellular loop (Du et al., 1997), $\mathrm{K}^{195}$ and $\mathrm{R}^{188}$ in TMII (Solano et al., 2001), $\mathrm{N}^{229}$ in TMIII and $\mathrm{Q}^{380}$ in TMVII of VPAC1 play an important role in VIP binding and probably could interact with the $\mathrm{D}^{3}$ residue of VIP (Chugunov et al., 2010). Thus, these results along with our data clearly indicate that the N-terminus of VIP interacts with the extracellular side of the VPAC1 core.

\section{THE N-TED DETERMINES THE SPECIFICITY OF THE VPAC1 RECEPTOR}

As mentioned above, VPAC1 and VPAC2 receptors do not discriminate between the two neuropeptides, VIP and PACAP. Moreover, some others VIP related-peptides are able to bind to human VPAC1 receptor with low affinity, including 
peptide histidine methionineamide (PHM), secretin, helodermin and GRF (Laburthe et al., 2007). Potency order being VIP $=$ PACAP $>$ helodermin $>$ PHM $>$ GRF $>>$ secretin. In this context, the development of specific ligands for VPAC1 and VPAC2 receptors represents a major goal. To develop a specific VPAC1 agonist, structure-function relationships analysis of VIP by a complete alanine scanning (Nicole et al., 2000) was used to rationally design the most potent and specific peptide for VPAC1 receptor currently available e.g., $\left[\mathrm{Ala}^{11,22,28}\right]$-VIP (Nicole et al., 2000). Indeed, this VIP derivative has an affinity 1000 times higher for the VPAC1 receptor, which is mainly involved in VIP anti-inflammatory action, than VPAC2 receptor (Delgado et al., 2004). As mentioned above a high selective antagonist of VPAC1 receptor (PG97-269) has been developed (Gourlet et al., 1997). Regarding VPAC2 receptor, the cyclic peptide analog of VIP [Ac-Glu ${ }^{8}$, OCH3-Tyr ${ }^{10}$, Lys $^{12}, \mathrm{Nle}^{17}, \mathrm{Ala}^{19}, \mathrm{Asp}^{25}, \mathrm{Leu}^{26}$, -Lys $^{27,28}$-VIP(cyclo 21-25)] or Ro 25-1392 is a potent and selective agonist (Xia et al., 1997). In our opinion, there is still no satisfactory VPAC2 receptor antagonist since PG 99-465, a VIP analog that antagonizes VIP action on VPAC2 receptor, which also has a significant agonist activity on human VPAC1 receptor (Moreno et al., 2000). Since recently, two non-peptide antagonists specific of VPAC1 (Harikrishnan et al., 2012) or VPAC2 (Chu et al., 2010) have been developed but they display a very low affinity for receptors.

The use of VIP photoaffinity probes associated to receptor mapping and Edman degradation demonstrated that VIP physically interacts with the N-ted of VPAC1 receptor (Couvineau et al., 2010). In order to get a high resolution structure of the VPAC1 receptor $\mathrm{N}$-ted, the production of large quantities of recombinant $\mathrm{N}$-ted protein in bacteria was performed (Couvineau et al., 2008). The 31-144 sequence of human VPAC1 receptor corresponding to the $\mathrm{N}$-ted sequence in which the signal peptide (Couvineau et al., 2004) has been deleted was subcloned in front of 6xHis (His-tag) and behind the thioredoxin sequence containing a thrombin cleavage site (Couvineau et al., 2008). The construction of the thioredoxin-N-ted-6xHis (Trx$\mathrm{N}$-ted-6xHis) fusion protein was chosen in order to increase the solubility of recombinant proteins as previously described for production of recombinant $\mathrm{N}$-ted of mouse CRF $2 \beta$ receptor (Grace et al., 2004). The soluble recombinant N-ted was purified onto Ni-NTA column and tested for its ability to bind VIP by using the influence of VIP binding on the intrinsic tryptophan fluorescence (ITF) of $\mathrm{W}^{67}, \mathrm{~W}^{73}$, and $\mathrm{W}^{110}$ residues which are present in the $\mathrm{N}$-ted sequence. Indeed, the presence of three tryptophan residues in the N-ted Sushi domain (Couvineau et al., 2008) represents a good fluorescent tag which can be used to measure the interaction between VIP and recombinant $\mathrm{N}$-ted. Based to the ITF parameters, the estimation of dissociation constants revealed a $\mathrm{Kd}$ of $0.54 \mu \mathrm{M}$ for VIP, $0.57 \mu \mathrm{M}$ for PACAP, and $1 \mu \mathrm{M}$ for PG96-269 (Couvineau et al., 2008). It should be noted that those $\mathrm{Kd}$ values were close to $\mathrm{Kd}$ values observed for others purified N-ted such as PAC1 receptor (Sun et al., 2007) and GIP receptor (Parthier et al., 2007). Moreover, the Kd of truncated VIP6-28 is very similar to $\mathrm{Kd}$ of native VIP $(0.54 \mu \mathrm{M}$ vs. $0.85 \mu \mathrm{M})$ demonstrating that the 6-28 VIP sequence is sufficient to interact with a low affinity to
Table 3 | Binding of VIP related-peptides to recombinant $\mathrm{N}$-ted.

\begin{tabular}{lc}
\hline Peptides & Kd $(\mu \mathbf{M})^{\mathbf{a}}$ \\
\hline VIP & $0.54 \pm 0.09$ \\
PG97-269 & $1.05 \pm 0.50$ \\
PACAP27 & $0.57 \pm 0.06$ \\
Helodermine & $2.54 \pm 0.71$ \\
PHM & $8.00 \pm 2.00$ \\
GRF & $10.12 \pm 0.98$ \\
Secretin & $16.00 \pm 1.00$ \\
VIP2-28 & $0.85 \pm 0.36$ \\
VIP1-12 & $N D^{b}$ \\
VIP18-28 & $N D$ \\
VIP1-9/21-28 & $N D$ \\
\hline
\end{tabular}

a The ITF of $W^{67}, W^{73}$, and $W^{110}$ residues from the purified $N$-ted was measured in $2 \mathrm{ml}$ of HEPES buffer $\mathrm{pH} 7.5$ containing $1 \mu \mathrm{M}$ purified $\mathrm{N}$-ted, in absence or presence of increasing concentration of peptides. Dissociation constants were determined from titration curves using analytical procedure developed by Bechet et al. (Bechet et al., 1986).

${ }^{b}$ Not detectable.

recombinant $\mathrm{N}$-ted (Table 3 ). In contrast, the deletion of large C-terminal (VIP1-12), central (VIP1-9/21-28) and N-terminal (VIP18-28) part of VIP abolishes totally the ability of truncated peptides to bind to recombinant N-ted (Table 3). These data clearly indicate that recombinant $\mathrm{N}$-ted is able to recognize with a low affinity the central and C-terminal part of VIP molecule. Using the same approach, the ability of VPAC1 recombinant N-ted to discriminate VIP related-peptides was investigated (Table 3). As shown in Table 2, the estimation of $\mathrm{Kd}$ was of $0.54 \mu \mathrm{M}, 0.57 \mu \mathrm{M}, 2.54 \mu \mathrm{M}, 8 \mu \mathrm{M}, 10.12 \mu \mathrm{M}$, and $16 \mu \mathrm{M}$ for VIP, PACAP, helodermin, PHM, GRF, and secretin respectively, indicating that the order of potency is similar to native receptor i.e., $\mathrm{VIP}=\mathrm{PACAP}>$ helodermin $>\mathrm{PHM}>\mathrm{GRF}>$ secretin (Laburthe et al., 2007). Taken altogether these results reveal that: (1) the recombinant $\mathrm{N}$-ted is able to bind with a low affinity and to discriminate VIP related-peptides suggesting that the VPAC1 $\mathrm{N}$-ted contains residues involved in the VPAC1 specificity; (2) the first transmembrane domain of VPAC1 contains three residues (see above) which interact with the first residue of VIP and these three residues are probably involved in the high affinity and the activation of the receptor (Figure 4B).

\section{CONCLUSION}

The VPAC receptors, in particular VPAC1, are very promising targets for the development of therapeutic molecules in various pathologies including asthma, chronic inflammation diseases (Crohn's disease, rhumatoid arthritis, septic shock, multiple sclerosis...) neurodegenerative disorders, schizophrenia. While new peptide derivatives specifically targeting VPAC receptor sub-types are now available, however, their very short half-life and the inconvenient related to their administration routes make them difficult to use in human therapy. The recent advance in the structural knowledge of the VPAC1 binding site should lead to the design of non-peptide receptor agonists and/or antagonists. The development of such 
molecules will represent an important overhang in the treatment of many human diseases.

\section{ACKNOWLEDGMENTS}

This work was supported by the Institut National de la Santé et de la Recherche Médicale, Centre National de la Recherche

\section{REFERENCES}

Abad, C., Martinez, C., Juarranz, M. G., Arranz, A., Leceta, J., Delgado, M., et al. (2003). Therapeutic effects of vasoactive intestinal peptide in the trinitrobenzene sulfonic acid mice model of Crohn's disease. Gastroenterology 124, 961-971.

Abad, C., Tan, Y. V., Cheung-Lau, G., Nobuta, H., and Waschek, J. A. (2012). VIP deficient mice exhibit resistance to lipopolysaccharide induced endotoxemia with an intrinsic defect in proinflammatory cellular responses. PLoS ONE 7:e36922. doi: 10.1371/journal.pone.0036922

Abad, C., Tan, Y. V., Lopez, R., Nobuta, H., Dong, H., Phan, P., et al. (2010). Vasoactive intestinal peptide loss leads to impaired CNS parenchymal T-cell infiltration and resistance to experimental autoimmune encephalomyelitis. Proc. Natl. Acad. Sci. U.S.A. 107, 19555-19560.

Bechet, J.-J., Houadjeto, M., and D’Albis, A. (1986). Active-site titration of enzymes at high concentration. Eur. J. Biochem. 161, 343-349.

Bourgault, S., Vaudry, D., Botia, B., Couvineau, A., Laburthe, M., Vaudry, H., et al. (2008). Novel stable PACAP analogs with potent activity towards the PAC1 receptor. Peptides 29, 919-932.

Brenneman, D. E., and Eiden, L. E. (1986). Vasoactive intestinal peptide and electrical activity influence neuronal survival. Proc. Natl. Acad. Sci. U.S.A. 83, 1159-1162.

Ceraudo, E., Hierso, R., Tan, Y. V., Murail, S., Rouyer-Fessard, C., Nicole, P., et al. (2012). Spatial proximity between the VPAC1 receptor and the amino terminus of agonist and antagonist peptides reveals distinct sites of interaction. FASEB J. 26, 2060-2071.

Ceraudo, E., Murail, S., Tan, Y. V., Lacapère, J. J., Neumann, J. M., Couvineau, A., et al. (2008). The vasoactive intestinal peptide (VIP) alpha-Helix up to $\mathrm{C}$ terminus interacts with the $\mathrm{N}$-terminal ectodomain of the human VIP/Pituitary adenylate cyclase-activating peptide 1 receptor: photoaffinity, molecular modeling, and dynamics. Mol. Endocrinol. 22, 147-155.

Christopoulos, A., Christopoulos, G., Morfis, M., Adawela, M., Laburthe, M., Couvineau, A., et al. (2002). Novel receptor partners and function of receptor activitymodifying proteins. J. Biol. Chem. 278, 3293-3297.

Chu, A., Caldwell, J. S., and Chen, characterization of a small molecule antagonist of human VPAC2 receptor. Mol. Pharmacol. 77, 95-101.

Chugunov, A. O., Simms, J., Poyner, D. R., Dehouck, Y., Rooman, M., Gilis, D., et al. (2010). Evidence that interaction between conserved residues in transmembrane helices 23 , and 7 are crucial for human VPAC1 receptor activation. Mol. Pharmacol. 78 394-401.

Couvineau, A., Ceraudo, E., Tan, Y. V., and Laburthe, M. (2010). VPAC1 receptor binding site: contribution of photoaffinity labeling approach. Neuropeptides 44, 127-132.

Couvineau, A., Gaudin, P., Maoret, J. J., Rouyer-Fessard, C., Nicole, P., and Laburthe, M. (1995). Highly conserved aspartate 68 , tryptophane 73 and glycine 109 in the Nterminal extracellular domain of the human VIP receptor are essential for its ability to bind VIP. Biochem. Biophys. Res. Commun. 206, 246-252.

Couvineau, A., and Laburthe, M. (2012a). The family B1 GPCR: structural aspects and interaction with accessory proteins. Curr. Drug Targets 13, 103-115.

Couvineau, A., and Laburthe, M. (2012b). VPAC receptors: strucinteraction with accessory proteins. Br. J. Pharmacol. 166, 42-50.

Couvineau, A., Lacapère, J. J., Tan, Y. V., Rouyer-Fessard, C., Nicole, P., and Laburthe, M. (2003). Identification of cytoplasmic domains of hVPAC1 receptor required for activation of adenylyl cyclase. J. Biol. Chem. 278, 24759-24766.

Couvineau, A., Robert, J. C., Ramdani, T., Lacapère, J. J., Rouyer-Fessard, Y. A. (2010). Identification and ture, molecular pharmacology and

Scientifique, Université Paris 7 and by a grant from the Association de Recherche sur la Polyarthrite. E. Ceraudo is supported by grant FDT20070910820 from the Fondation pour la Recherche Médicale and by an « Inter-university Poles of Attraction Program $\gg(\mathrm{PAI})$ from the Université Libre de Bruxelles (ULB), Belgium.

C., and Laburthe, M. (2008). Production and purification of large quantities of the functional $\mathrm{N}$-terminal ectodomain of human VPAC1 receptor. J. Mol. Neurosci. 36, 249-253.

Couvineau, A., Rouyer-Fessard, C. Darmoul, D., Maoret, J. J., Carrero, I., Ogier-Denis, E., et al. (1994). Human intestinal VIP receptor: cloning and functional expression of two cDNA encoding proteins with different N-terminal domains. Biochem. Biophys. Res. Commun. 200, 769-776.

Couvineau, A., Rouyer-Fessard, C., Fournier, A., St Pierre, S., Pipkorn, R., and Laburthe, M. (1984). Structural requirements for VIP interaction with specific receptors in human and rat intestinal membranes: effect of nine partial sequences. Biochem. Biophys. Res. Commun. 121, 493-498.

Couvineau, A., Rouyer-Fessard, C., and Laburthe, M. (2004). Presence of a $\mathrm{N}$-terminal signal peptide in class II G protein-coupled receptors: crucial role for expression of the human VPAC1 receptor. Regul. Pept. 123 181-185.

Couvineau, A., Rouyer-Fessard, C. Maoret, J. J., Gaudin, P., Nicole, P., and Laburthe, M. (1996a). Vasoactive intestinal peptide (VIP) 1 receptor. Three nonadjacent amino acids are responsible for species selectivity with respect to recognition of peptide histidine isoleucineamide. J. Biol. Chem. 271, 12795-12800.

Couvineau, A., Fabre, C., Gaudin P., Maoret, J. J., and Laburthe, M. (1996b). Mutagenesis of $\mathrm{N}$ glycosylation sites in the human vasoactive intestinal peptide 1 receptor. Evidence that asparagine 58 or 69 is crucial for correct delivery of the receptor to plasma membrane. Biochemistry 35 1745-1752.

Dejda, A., Sokołowska, P., and Nowak, J. Z. (2005). Neuroprotective potential of three neuropeptides PACAP, VIP and PHI. Pharmacol. Rep. 57, 307-320.

Delgado, M., Abad, C., Martinez, C., Leceta, J., and Gomariz, R. P. (2001). Vasoactive intestinal peptide prevents experimental arthritis by downregulating both autoimmune and inflammatory components of the disease. Nat. Med. 7, 563-568.

Delgado, M., and Ganea, D. (2011). Vasoactive intestinal peptide: a neuropeptide with pleiotropic immune functions. Amino Acids 11, 1184-1188.

Delgado, M., Pozo, D., and Ganea, D. (2004). The significance of vasoactive intestinal peptide in immunomodulation. Pharmacol. Rev. 56, 249-290.

Dickson, L., and Finlayson, K. (2009). VPAC and PAC receptors: from ligands to function. Pharmacol. Ther. 121, 294-316.

Dogrukol-Ak, D., Tore, F., and Tuncel, N. (2004). Passage of VIP/PACAP/secretin family across the blood-brain barrier: therapeutic effects. Curr. Pharm. Des. 10, 1325-1340.

Du, K., Nicole, P., Couvineau, A., and Laburthe, M. (1997). Aspartate 196 in the first extracellular loop of the human VIP1 receptor is essential for VIP binding and VIP-stimulated cAMP production. Biochem. Biophys. Res. Commun. 230, 289-292.

Fahrenkrug, J. (2001). Gut/brain peptides in the genital tract: VIP and PACAP. Scand. J. Clin. Lab. Invest. 234, 35-39.

Fernandez-Montesinos, R., Castillo, P. M., Klippstein, R., GonzalezRey, E., Mejias, J. A., Zaderenko, A. P., et al. (2009). Chemical synthesis and characterization of silver-protected vasoactive intestinal peptide nanoparticles. Nanomedicine (Lond.) 4, 919-930.

Firestein, G. S. (2001). VIP: a very important protein in arthritis. Nat. Med. 7, 537-538.

Fredrikson, R., and Schiöth, B. (2006). "G Protein-coupled receptors in human genome," in Ligand Design for G ProteinCoupled Receptors, vol. 30, ed D. Rognan (Weinheim: Wiley-VCH), $1-27$.

Gonzalez-Rey, E., Chorny, A., Fernandez-Martin, A., Varela, N., and Delgado, M. (2005). Vasoactive intestinal peptide family as a 
therapeutic target for Parkinson's disease. Expert Opin. Ther. Targets 9, 923-929.

Gourlet, P., De Neef, P., Cnudde, J., Waelbroeck, M., and Robberecht, P. (1997). In vitro properties of a high affinity selective antagonist of the VIP1 receptor. Peptides 18, 1555-1560.

Gozes, I., Bardea, A., Reshef, A., Zamostiano, R., Zhukovsky, S., Rubinraut, S., et al. (1996). Neuroprotective strategy for Alzheimer disease: intranasal administration of a fatty neuropeptide. Proc. Natl. Acad. Sci. U.S.A. 93, 427-432.

Gozes, I., Divinsky, I., Pilzer, I., Fridkin, M., Brenneman, D. E., and Spier, A. D. (2003). From vasoactive intestinal peptide (VIP) through activity-dependent neuroprotective protein (ADNP) to NAP: a view of neuroprotection and cell division. J. Mol. Neurosci. 20, 315-322.

Grace, C. R., Perrin, M. H., DiGruccio, M. R., Miller, C. L., Rivier, J. E., Vale, W. W., et al. (2004). NMR structure and peptide hormone binding site of the first extracellular domain of a type B1 G protein-coupled receptor. Proc. Natl. Acad. Sci. U.S.A. 101, 12836-12841.

Groneberg, D. A., Rabe, K. F., and Fischer, A. (2006). Novel concepts of neuropeptide-based drug therapy: vasoactive intestinal polypeptide and its receptors. Eur. J. Pharmacol. 533, 182-194.

Harikrishnan, L. S., Srivastava, N., Kayser, L. E., Nirschl, D. S., Kumaragurubaran, K., Roy, A., et al. (2012). Identification and optimization of small molecule antagonists of vasoactive intestinal peptide receptor-1 (VIPR1). Bioorg. Med. Chem. Lett. 22, 2287-2290.

Harikumar, K. G., Morfis, M. M., Lisenbee, C. S., Sexton, P. M., and Miller, L. J. (2006). Constitutive formation of oligomeric complexes between family B G protein-coupled vasoactive intestinal polypeptide and secretin receptors. Mol. Pharmacol. 69, 363-373.

Harmar, A. J., Fahrenkrug, J., Gozes, I., Laburthe, M., May, V., Pisegna, J. R., et al. (2012). Pharmacology and functions of receptors for vasoactive intestinal peptide and pituitary adenylate cyclaseactivating polypeptide: IUPHAR review 1. Br. J. Pharmacol. 166, 4-17.
Hoare, S. R. J. (2005). Mechanism of peptide and nonpeptide ligand binding to class B G-proteincoupled receptors. Drug Discov. Today 10, 417-427.

Ishihara, T., Nakamura, S., Kaziro, Y., Takahashi, T., Takahashi, K. and Nagata, S. (1991). Molecular cloning and expression of a cDNA encoding the secretin receptor. EMBO J. 10, 1635-1641.

Ishihara, T., Shigemoto, R., Mori, K., Takahashi, K., and Nagata, S. (1992). Functional expression, and tissue distribution of a novel receptor for vasoactive intestinalpolypeptide. Neuron 8, 811-819.

Jaakola, V. P., Griffith, M. T., Hanson, M. A., Cherezov, V., Chien, E. Y. Lane, J. R., et al. (2008). The 2.6 angstrom crystal structure of a human A2A adenosine receptor bound to an antagonist. Science 322, 1211-1217.

Kumar, S., Pioszak, A., Zhang, C., Swaminathan, K., and $\mathrm{Xu}, \mathrm{H}$ E. (2011). Crystal structure of the PAC1R extracellular domain unifies a consensus fold for hormone recognition by class B G-protein coupled receptors. PLoS ONE 6:e19682. doi: 10.1371/ journal.pone.0019682

Laburthe, M., Couvineau, A., and Marie, J. C. (2002). VPAC receptors for VIP and PACAP. Receptors Channels 8, 137-153.

Laburthe, M., Couvineau, A., and Tan, V. (2007). Class II G proteincoupled receptors for VIP and PACAP: structure, models of activation and pharmacology. Peptides 28, 1631-1639.

Lambeir, A. M., Durinx, C., Proost, P., Van Damme, J., Scharpé, S., and De Meester, I. (2001). Kinetic study of the processing by dipeptidyl-peptidase IV/CD26 of neuropeptides involved in pancreatic insulin secretion. FEBS Lett. 507 327-330.

Leceta, J., Gomariz, R. P., Martinez, C., Carrión, M., Arranz, A., and Juarranz, Y. (2007). Vasoactive intestinal peptide regulates Th17 function in autoimmune inflammation. Neuroimmunomodulation 14, 134-138.

Lutz, E. M., Sheward, W. J., West, K. M., Morrow, J. A., Fink, G., and Harmar, A. J. (1993). The VIP2 receptor: molecular characterisation of a cDNA encoding a novel receptor for vasoactive intestinal peptide. FEBS Lett. 334 3-8.
Marie, J. C., Rouyer-Fessard, C. Couvineau, A., Nicole, P., Devaud, H., El Benna, J., et al. (2003). Serine 447 in the carboxyl tail of human VPAC1 receptor is crucial for agonist-induced desensitization but not internalization of the receptor. Mol. Pharmacol. 64, 1565-1574.

Moody, T. W., Ito, T., Osefo, N. and Jensen, R. T. (2011). VIP and PACAP: recent insights into their functions/roles in physiology and disease from molecular and genetic studies. Curr. Opin. Endocrinol. Diabetes Obes. 18 , 61-67.

Moreno, D., Gourlet, P., De Neef, P., Cnudde, J., Waelbroeck, M., and Robberecht, P. (2000). Development of selective agonists and antagonists for the human vasoactive intestinal peptide VPAC2 receptor. Peptides 21 1543-1549.

Neumann, J. M., Couvineau, A. Murail, S., Lacapère, J. J., Jamin, N., and Laburthe, M. (2008). Class-B GPCR activation: is ligand helixcapping the key? Trends Biochem. Sci. 33, 314-319.

Nicole, P., Lins, L., Rouyer-Fessard, C., Drouot, C., Fulcrand, P., Thomas, A., et al. (2000). Identification of key residues for interaction of vasoactive intestinal peptide with human VPAC1 and VPAC2 receptors and development of a highly selective VPAC1 receptor agonist. J. Biol. Chem. 275, 24003-24012.

Onyüksel, H., Mohanty, P. S., and Rubinstein, I. (2009). VIP-grafted sterically stabilized phospholipid nanomicellar 17-allylamino17-demethoxy geldanamycin: a novel targeted nanomedicine for breast cancer. Int. J. Pharm. 365, 157-161.

Pal, K., Melcher, K., and $\mathrm{Xu}$, H. E. (2012). Structure and mechanism for recognition of peptide hormones by Class B G-protein-coupled receptors. Acta Pharmacol. Sin. 33, 300-311.

Parthier, C., Kleinschmidt, M., Neumann, P., Rudolph, R., Manhart, S., Schlenzig, D., et al. (2007). Crystal structure of the incretin-bound extracellular domain of a $G$ protein-coupled receptor. Proc. Natl. Acad. Sci. U.S.A. 104, 13942-13947.

Parthier, C., Reedtz-Runge, S. Rudolph, R., and Stubbs, M. T. (2009). Passing the baton in class B GPCRs: peptide hormone activation via helix induction? Trends Biochem. Sci. 34, 303-310.

Said, S. I., and Mutt, V. (1970). Polypeptide with broad biological activity: isolation from small intestine. Science 169, 1217-1228.

Shoichet, B. K., and Kobilka, B. K. (2012). Structure-based drug screening for G-protein-coupled receptors. Trends Pharmacol. Sci. 33, 268-272.

Solano, R. M., Langer, I., Perret, J., Vertongen, P., Juarranz, M. G., Robberecht, P., et al. (2001). Two basic residues of the h-VPAC1 receptor second transmembrane helix are essential for ligand binding and signal transduction. J. Biol. Chem. 276, 1084-1088.

Sreedharan, S. P., Patel, D. R., Huang, J. X., and Goetzl, E. J. (1993). Cloning and functional expression of a human neuroendocrine vasoactive intestinal peptide receptor. Biochem. Biophys. Res. Commun. 193, 546-553.

Sun, C., Song, D., Davis-Taber, R. A., Barrett, L. W., Scott, V. E., Richardson, P. L., et al. (2007). Solution structure and mutational analysis of pituitary adenylate cyclase-activating polypeptide binding to the extracellular domain of PAC1-RS. Proc. Natl. Acad. Sci. U.S.A. 104, 7875-7880.

Tan, Y. V., Couvineau, A., and Laburthe, M. (2004). Diffuse pharmacophoric domains of vasoactive intestinal peptide (VIP) and further insights into the interaction of VIP with the N-terminal ectodomain of human VPAC1 receptor by photoaffinity labeling with [Bpa6]-VIP. J. Biol. Chem. 279, 38889-38894.

Tan, Y. V., Couvineau, A., Murail, S., Ceraudo, E., Neumann, J. M., Lacapère, J. J., et al. (2006). Peptide agonist docking in the $\mathrm{N}$-terminal ectodomain of a class II G proteincoupled receptor, the VPAC1 receptor. Photoaffinity, NMR, and molecular modeling. J. Biol. Chem. 281, 12792-12798

Tan, Y. V., Couvineau, A., Van Rampelbergh, J., and Laburthe, M. (2003). Photoaffinity labeling demonstrates physical contact between vasoactive intestinal peptide and the N-terminal ectodomain of the human VPAC1 receptor. J. Biol. Chem. 278, 36531-36536.

Tan, Y. V., and Waschek, J. A. (2011). Targeting VIP and PACAP receptor 
signalling: new therapeutic strategies in multiple sclerosis. ASN Neuro 3, e00065.

Vacic, V., McCarthy, S., Malhotra, D., Murray, F., Chou, H. H., Peoples, A., et al. (2011). Duplications of the neuropeptide receptor gene VIPR2 confer significant risk for schizophrenia. Nature 471, 499-503.

Watkins, H. A., Au, M., and Hay, D. L. (2012). The structure of secretin family GPCR peptide ligands: implications for receptor pharmacology and drug development. Drug Discov. Today 17, 1006-1014.

Xia, M., Sreedharan, S. P., Bolin, D. R., Gaufo, G. O., and Goetzl, E. J. (1997). Novel cyclic peptide agonist of high potency and selectivity for the type II vasoactive intestinal peptide receptor. J. Pharmacol. Exp. Ther. 281, 629-633.

Conflict of Interest Statement: The authors declare that the research was conducted in the absence of any commercial or financial relationships that could be construed as a potential conflict of interest.

Received: 31 August 2012; paper pending published: 26 September 2012; accepted: 26 October 2012; published online: 16 November 2012.

Citation: Couvineau A, Ceraudo E, Tan $Y-V$, Nicole $P$ and Laburthe $M$ (2012) The VPAC1 receptor: structure and function of a class B GPCR prototype. Front. Endocrin. 3:139. doi: 10.3389/ fendo.2012.00139
This article was submitted to Frontiers in Neuroendocrine Science, a specialty of Frontiers in Endocrinology.

Copyright (c) 2012 Couvineau, Ceraudo, Tan, Nicole and Laburthe. This is an open-access article distributed under the terms of the Creative Commons Attribution License, which permits use, distribution and reproduction in other forums, provided the original authors and source are credited and subject to any copyright notices concerning any third-party graphics etc. 